\title{
Caracterización de alteraciones craneofaciales en población con necesidades especiales: autismo y retardo mental. Revisión sistemática de la literatura
}

\author{
Craniofacial Abnormalities in Special-Needs Population. \\ Systematic review of Literature
}

Carol Renata Erazo Cerón Odontóloga, odontopediatra, estudiante del posgrado de Ortodoncia, Pontificia Universidad Javeriana, Bogotá, Colombia.

Gloria Ángela Carrillo Estrada Odontóloga, odontopediatra, coordinadora del posgrado de Odontopediatría, Pontificia Universidad Javeriana, Bogotá, Colombia.

Juliana Velosa Porras

Odontóloga, epidemióloga clínica, docente, Pontificia Universidad Javeriana, Bogotá, Colombia.

CÓMO CITAR ESTE ARTÍCULO Erazo CR, Carrillo GA, Velosa J. Caracterización de alteraciones craneofaciales en población con necesidades especiales: autismo y retardo mental. Revisión sistemática de la literatura. Univ Odontol. 2014 Jul-Dic; 33(71): _. http://dx.doi. org/10.11144/Javeriana.uo33-71.cacp

doi:10.11144/Javeriana.uo33-71.cacp

Recibido para publicación: 20/06/2014 Aceptado para publicación: 23/09/2014

Disponible en: http://www.javeriana.edu.co/ universitasodontologica

\section{RESUMEN}

Antecedentes: en los pacientes con discapacidad física y mental se han encontrado anomalías orales y dentales que pueden llevar a un mal funcionamiento del complejo estomatognático. Ello genera disfunciones en el habla, la masticación, la deglución y la respiración. La identificación de las características craneofaciales de estos pacientes permitirá orientar y efectuar una intervención temprana de cualquier problema dental o esquelético a fin de lograr una oclusión normal y una mejoría en las funciones masticatorias, el desarrollo orofacial y el bienestar psicosocial del paciente. Propósito: identificar mediante una revisión sistemática de la literatura las alteraciones craneofaciales de pacientes con necesidades especiales (retardo mental y autismo) que permitan orientar su proceso diagnóstico. Métodos: se realizó una revisión sistemática de la literatura mediante la búsqueda en las bases de datos electrónicas: Medline, Cochrane-BVS, EBSCOHost, LiLACS, ScienceDirect, Embase y Ovid. Se utilizaron los descriptores: "trastorno autista" y "discapacidad intelectual" (autistic disorder AND intellectual disability), en combinación con "anormalidades craneofaciales", "maloclusión" y "hábitos orales" (craniofacial abnormalities; malocclusion AND oral habits). Resultados: la evidencia disponible sobre características craneofaciales propias de pacientes con retardo mental y autismo fue limitada. Ello no permitió realizar un análisis y comparaciones estadísticas, hecho que impide generalizar los resultados. Conclusiones: no se encontró evidencia disponible sobre características craneofaciales en la población con retardo mental y autismo. Las anomalías dentofaciales más frecuentemente reportadas en pacientes con discapacidad mental y autismo fueron maloclusión y bruxismo, sin distinción de edad o sexo.

PALABRAS CLAVE

anomalías craneofaciales; trastorno autista; hábitos orales; maloclusión; necesidades especiales; retardo mental

\section{ÁREAS TEMÁTICAS}

Diagnóstico; trastornos del desarrollo infantil; trastornos mentales diagnosticados en la infancia

\section{ABSTRACT}

Background: Oral and/or dental abnormalities have been found in patients with physical and/or mental disabilities, which may lead to malfunctions of the stomatognathic system, including speech, occlusion, and breathing dysfunctions. The identification of craniofacial issues among these patients will guide early dental and skeletal interventions, in order to achieve a normal occlusion, improved masticatory function, orofacial development, and psychosocial well-being of the patient. Purpose: To identify craniofacial abnormalities of special-needs patients (with intellectual disabilities and autism), through a systematic review of the literature, to guide the diagnostic process. Methods: The literature review was performed by searching the electronic databases: Medline, Cochrane-BVS, EBSCOHost, LiLACS, ScienceDirect, Embase, and Ovid, with the following descriptors: "autistic disorder" AND "intellectual disability," in combination with "craniofacial abnormalities," "malocclusion," AND "oral habits." Results: Evidence on craniofacial characteristics typical of patients with intellectual disability and autism was limited. Therefore, it was not possible to perform analysis and statistical comparisons and to generalize the results. Conclusion: There was not available evidence on craniofacial characteristics in people with intellectual disability and autism. The most frequently reported dentofacial abnormalities among these patients were malocclusion and bruxism, regardless of age or gender.

\section{KEYWORDS}

Autistic disorder; craniofacial abnormalities; intellectual disability; malocclusion; oral habits; special needs

\section{THEMATIC FIELDS}

Child development disorders; diagnostics; mental disorders diagnosed during childhood 


\section{INTRODUCCIÓN}

La armonía en la morfología facial y el equilibrio entre sus componentes son necesarios para una estética y función adecuadas. Con frecuencia, las diferentes estructuras que componen el sistema estomatognático pueden estar alteradas en personas con trastornos físicos o mentales, lo que puede llevar a un mal funcionamiento (1-7). Al respecto, Brown y Schodel (3), Dinesh y colaboradores (4) y Vigild (5) reportaron una mayor presencia de maloclusión en individuos con alguna limitación de tipo físico o mental (48-86 \%), en comparación con la población general (43-55 \%) $(6,7)$. Las malformaciones congénitas, los trastornos musculoesqueléticos (como la parálisis cerebral), los trastornos esqueléticos de crecimiento y la discinesia orofacial pueden llevar al desarrollo de maloclusiones (4) que varían en función de la discapacidad y de su origen (físico o mental) (7).

Dentro de los factores que contribuyen a la mayor prevalencia de maloclusiones en pacientes con necesidades especiales se encuentran principalmente: deformidades craneofaciales, alteraciones de crecimiento y desarrollo, postura anormal de la lengua, trastornos neuromusculares, alteraciones dentales y presencia de hábitos orales $(3,5)$. Estos, a su vez, desencadenan en una serie de disfunciones en el habla, la masticación, la deglución y la respiración (3). Atmetlla y colaboradores (6) reportaron alta prevalencia de hábitos orales parafuncionales como bruxismo, onicofagia y respiración oral en un grupo de niños con déficit de atención e hiperactividad, además de características craneofaciales en las que predominaron el biotipo facial leptoprosopo, la dolicocefalia y el perfil convexo. No obstante, estos hallazgos no se relacionaron con un tipo de maloclusión específico, por lo que se sugiere que estas características, junto con las dentales, pueden ser fenotípicas en estos niños. Los autores recomiendan la necesidad de mayor investigación al respecto.

De acuerdo con Utomi y Onyeaso (7), Somani y colaboradores (1) y Bhowate y colaboradores (2), no siempre pueden suplirse las necesidades de tratamiento ortodóntico en niños con discapacidades mentales, debido a factores ambientales y a características individuales. Entre estas características se cuentan condiciones físicas, mentales, sensoriales, de comportamiento, cognitivas, emocionales y médicas. Además, algunas son propias de estos pacientes, como bruxismo, sialorrea, gingivitis, caries y maloclusión, que pueden llevar al desarrollo inadecuado y mal funcionamiento del complejo estomatognático (7-9).

La identificación de las características craneofaciales, dentales y comportamentales ayuda a establecer un diagnóstico oportuno, a partir del cual se realice un abordaje multidisciplinario en estos pacientes. El odontólogo tratante debe estar familiarizado con los indicadores de trastornos para poder identificarlos y orientar a los padres sobre la posible intervención temprana de cualquier problema dental o esquelético, con el fin de ayudar a lograr una oclusión normal y una mejoría en las funciones masticatorias, lo que se traducirá en una reducción de la prevalencia de las maloclusiones, en un mejor desarrollo orofacial y en el bienestar psicosocial del paciente.

El trastorno autista y el retardo mental son dos de las patologías que hacen parte de las discapacidades del desarrollo, en las cuales se ha reportado la presencia de anomalías craneofaciales. Sin embargo, existe poca literatura al respecto. El trastorno autista o autismo se considera un síndrome o conjunto de signos y síntomas que hace parte de los llamados trastornos generalizados del desarrollo no especificados. Estos trastornos afectan tres dominios: a) la relación o interacción social, b) las habilidades de comunicación y comprensión del lenguaje y c) el repertorio restringido de intereses y comportamientos. No se conoce la causa exacta de este trastorno aunque se ha relacionado con factores genéticos, ambientales $y$, en algunos casos, con la existencia de un mal funcionamiento del sistema nervioso central, fundamentalmente del cerebro y cerebelo, pero aún se desconoce cómo ocurre esto. Se manifiesta generalmente antes de los tres años de edad, en diferentes niveles intelectuales y trastornos neurobiológicos. Algunas personas con autismo tienen desarrollo emocional o del lenguaje alterado. Otras coexisten con discapacidades como retardo mental o epilepsia (8-12). Dentro de los hallazgos orofaciales en esta población se ha reportado paladar hendido asociado con anomalías de línea media cerebral, como en el síndrome de alcohol fetal u otros trastornos del desarrollo neurológico $(13,14)$. También se han reportado paladar ojival o profundo, lengua fisurada, glositis migratoria, mala inserción de frenillos y alteraciones del desarrollo dental, como opacidades dentales, líneas neonatales amplias y alteraciones estructurales del esmalte $(13,15-17)$, lengua saburral, facetas de desgaste y mayor incidencia de hábitos orales como bruxismo, onicofagia, queilofagia y mordedura de objetos (16-18). Por otra parte, la 
alta prevalencia de dolicocefalia, no relacionada con macrocefalia, es una característica que distingue al grupo de pacientes con autismo de pacientes de grupos controles normales. De acuerdo con lo referido en la literatura, no hay un único patrón de crecimiento de la cabeza o el cerebro en todos los niños con autismo. La variabilidad en el tamaño de la cabeza y el cerebro y la velocidad y dirección de crecimiento de la cabeza y el cerebro parecen ser parte del autismo $(12,13)$. En relación con lo anterior, Cheung y colaboradores (19) encontraron una mayor distancia interorbital consistente con la expansión del tamaño de la cabeza en el autismo.

El retardo mental (RM) se caracteriza por presentar una función intelectual por debajo del promedio general en pruebas (coeficiente intelectual $<70$ ) y una disminución de las habilidades adaptativas, en el cual existe un estado particular de funcionamiento mental que inicia en la infancia o antes de los 18 años, que es el trastorno del desarrollo más común (20-22). El RM puede acompañarse de cualquier otro trastorno somático o mental (22).

Waldrop y colaboradores (13) reportan que en algunos pacientes con necesidades especiales existen pequeñas desviaciones estructurales en el desarrollo físi$\mathrm{co}$, las cuales surgen con mayor frecuencia en niños con disfunción mínima del sistema nervioso central, trastornos de conducta y retardo mental. Tales desviaciones o anomalías físicas menores se consideran resultado de trastornos morfogenéticos. Se piensa que son "variantes morfogenéticas informativas" o "malformaciones menores" que pretenden denotar errores morfogenéticos leves de origen prenatal. La correlación positiva entre la presencia de anomalías menores, alteraciones de conducta y RM se ha determinado en diferentes estudios que confirman una alta incidencia de estas anomalías en niños con retardo mental, quienes en su mayoría presentan de cinco a seis anomalías en comparación con niños sanos, en quienes se pueden encontrar una, dos o ninguna (21-25).

Como resultado de la mala configuración craneofacial, en niños con discapacidad visual y RM se presentan con alta frecuencia anomalías asociadas al mal control muscular y mal funcionamiento de la cavidad oral. Se incluyen: diastema de línea media, microdoncia, dientes retenidos, dens invaginatus, frenillo sobreinsertado en labio superior y lengua $(1,26)$, lengua fisurada con punteado suave e hipodoncia (21-23), además de una frecuencia significativamente mayor de maloclusión severa y agenesias dentales $(24,27)$. La maloclusión se presenta en forma de mordida abierta, mordida cruzada y apiñamiento en casi un 60 $\%$. Otras anomalías que tienen lugar son dientes ausentes (30\%), hipoplasias dentales (30\%), diastemas interdentales (40\%) y paladar profundo (ojival) en al menos un $20 \%$ de los niños con RM. Es importante saber que los niños con RM presentan, además, mala higiene bucal, caries y cálculos gingivales (70-80 \%) y enfermedad periodontal $(27,28)$. Además, existe evidencia de que los pacientes con trastornos mentales son más vulnerables a desarrollar signos de trastornos temporomandibulares y desgastes dentales excesivos, asociados estos a la existencia de hábitos como bruxismo o apretamiento dental parafuncional (27).

Gershater (1972) y Sassouni (1967), citados por Friedlander y colaboradores (28), también informaron sobre la existencia de una fuerte interrelación entre la actividad muscular del complejo estomatognático y el cambio en la morfología esquelética y dental. Esto conduce a maloclusiones en pacientes con retardo mental y se ha relacionado como un factor importante para el diagnóstico de retardo mental, dada la presencia de patrones craneofaciales inadecuados de deglución, habla, masticación y respiración.

El manejo del complejo orofacial de los pacientes con discapacidad física o mental plantea retos para el profesional que acepta la responsabilidad de brindar una atención integral y un acompañamiento a las familias, a quienes debe ayudar a adaptarse y comprender la complejidad de la anomalía y las necesidades orales relacionadas. Para ello, se debe tener conocimiento de los factores asociados con su comportamiento y los efectos de la enfermedad en el crecimiento, la función y la apariencia (7,29-32). La falta de una intervención oportuna en estos pacientes puede causar la progresión de su trastorno, que puede dar lugar a un dolor innecesario, aumento de las necesidades y costos del tratamiento, malas experiencias del tratamiento y una disminución de la salud oral. Dada la importancia de identificar rasgos físicos que orienten el proceso diagnóstico de pacientes con necesidades especiales, se planteó realizar una revisión sistemática para identificar las alteraciones craneofaciales asociadas con RM y autismo reportadas en la literatura.

\section{MATERIALES Y MÉTODOS}

Se llevó a cabo una revisión sistemática de la literatura sobre anormalidades orales y craneofaciales de pacientes con diagnóstico de RM y autismo. Se 
incluyeron artículos producto de ensayos clínicos controlados aleatorizados, estudios observacionales descriptivos, estudios longitudinales, estudios observacionales analíticos y estudios agregativos que incluyeran población con diagnóstico de autismo o RM, y estudios en humanos sin intervención ortodóntica previa en quienes el desenlace observado fuera la descripción de características craneofaciales de la población de estudio. No se incluyeron estudios de tipo experimental, informes de casos, cartas y narrativas, revisiones históricas o estudios en los que los pacientes hubieran recibido algún tipo de intervención ortodóntica preventiva, interceptiva o correctiva.

\section{Estrategia de la búsqueda}

Las búsquedas sistemáticas se realizaron en siete bases de datos electrónicas: Medline, Cochrane-BVS, EBSCOHost, LiLACS, ScienceDirect, Embase y Ovid. Se utilizaron las palabras clave trastorno autista $y$ discapacidad intelectual (autistic disorder e intelectual disability), en combinación con anormalidades craneofaciales, maloclusión y hábitos orales (craniofacial abnormalities, malocclusion and oral habits). La búsqueda se limitó a publicaciones realizadas entre 2003 y 2013, en español e inglés, de estudios realizados en humanos de diferentes grupos etarios: prescolares (1-6 años), escolares (7-12 años), infantes (1-12 años) y adolescentes (13-18 años).

\section{Evaluación y selección}

Se realizó una evaluación inicial de cada artículo, primero por el título $(n=1763)$ y luego por el resumen $(n=13)$ de forma independiente, teniendo en cuenta los criterios de inclusión y exclusión. Se obtuvo un acuerdo perfecto entre los autores (100 \%) en cuanto a la decisión de incluir o excluir los estudios revisados. Se seleccionaron así cuatro artículos.

Posteriormente, se resumieron los artículos incluidos. Se extrajo la información necesaria para evaluar la calidad metodológica de cada estudio, con el fin de asegurar la precisión de la información. Con los datos resultantes se creó una instrumento de recolección y evaluación de datos con los siguientes elementos: referencia; diseño del estudio; participantes/muestra; características en pacientes con RM; características en pacientes con autismo; relación causa-efecto hábitos y características craneofaciales del RM y autismo; diferencias de las características craneofaciales según el grado de severidad del RM y autismo; cambios de características craneofaciales según la edad en pacientes con RM y autismo; resultados; conclusiones; tipo de evidencia; tipo de recomendación; riesgo de sesgo.

\section{Evaluación de la heterogeneidad}

A partir del resumen de cada artículo, se evaluó la heterogeneidad de los resultados. Según este criterio se identificaron: a) el diseño del estudio y el periodo de evaluación; b) los participantes (número y edad de los sujetos); b) el diagnóstico médico de la discapacidad; c) las características orales y faciales descritas en pacientes con RM y con autismo; d) la relación causa-efecto de los hábitos orales y las características craneofaciales del RM y autismo; e) las diferencias en las características craneofaciales según el grado de severidad del RM y del autismo; f) los cambios de las características craneofaciales según la edad en pacientes con RM y autismo; g) el método de evaluación; h) la idoneidad del análisis estadístico, e i) el sesgo de publicación.

\section{Evaluación de la calidad}

Dos de los investigadores registraron la calidad metodológica de los estudios incluidos. El tipo de evidencia, el grado de recomendación y el riesgo de sesgo de cada uno de los estudios se evaluaron de acuerdo con los criterios de las Guías del Centro de Medicina Basada en la Evidencia (2008) y el Journal of the American Medical Association.

\section{Extracción de datos y análisis}

La extracción de la información se centró en el diseño del estudio, la población y muestra, las características craneofaciales asociadas con RM y con autismo, la relación causa-efecto entre los hábitos orales y las características craneofaciales de los pacientes con RM y autismo, las diferencias en las características craneofaciales de acuerdo con el grado de severidad del RM y el autismo, los cambios en las características craneofaciales de pacientes con RM y autismo de acuerdo con la edad y los resultados reportados. Posteriormente, los datos serían procesados con ayuda del programa RevMan 5.

\section{RESULTADOS}

La búsqueda en las bases de datos se realizó durante agosto y septiembre de 2013 (tabla 1). De la búsqueda inicial se obtuvieron 1763 títulos de artículos científicos de los cuales, de acuerdo con el título, se seleccionaron 13 que cumplían con los objetivos de la revisión (tabla 2). De esta preselección, luego de evaluar los resúmenes, se escogieron 4 estudios como número final para el análisis completo (anexo). 
TABLA 1

RESULTADO DE LA BÚSQUEDA POR CADA BASE DE DATOS

\begin{tabular}{|c|c|c|c|}
\hline Base de datos & Parámetros de búsqueda & Términos de búsqueda & Resultado \\
\hline \multirow[t]{7}{*}{ Medline } & $\begin{array}{l}\text { Article type: Classical Article, Clinical } \\
\text { Trial, Controlled Clinical Trial, Meta- }\end{array}$ & $\begin{array}{l}\text { autistic disorder AND craniofacial } \\
\text { abnormalities }\end{array}$ & 5 \\
\hline & Analysis, Randomized Controlled Trial, & autistic disorder AND malocclusion & 0 \\
\hline & Review Systematic Reviews. & autistic disorder AND oral habits & 0 \\
\hline & Publication dates: 10 years & intellectual disability AND craniofacial & 77 \\
\hline & Species; Humans & abnormalities & \\
\hline & Languages: English, Spanish & intellectual disability AND maloclussion & 5 \\
\hline & $\begin{array}{l}\text { Ages; Preschool Child: } 2-5 \text { years, Child: } \\
6-12 \text { years, Adolescent: } 13-18 \text { years }\end{array}$ & intellectual disability AND oral habits & 2 \\
\hline \multirow[t]{7}{*}{ Cochrane- BVS } & Revisiones: todas & autistic disorder AND craniofacial & 0 \\
\hline & Campo de búsqueda: palabras & abnormalities & \\
\hline & & autistic disorder AND malocclusion & 0 \\
\hline & & autistic disorder AND oral habits & 1 \\
\hline & & $\begin{array}{l}\text { intellectual disability AND craniofacial } \\
\text { abnormalities }\end{array}$ & 1 \\
\hline & & intellectual disability AND maloclussion & 0 \\
\hline & & intellectual disability AND oral habits & 0 \\
\hline \multirow[t]{7}{*}{ EBSCOHost } & $\begin{array}{l}\text { Todas las bases de datos (excepto } \\
\text { MEDLINE) }\end{array}$ & $\begin{array}{l}\text { autistic disorder AND craniofacial } \\
\text { abnormalities }\end{array}$ & 1 \\
\hline & Modos de búsqueda: Boleano/frase & autistic disorder AND malocclusion & 10 \\
\hline & Fecha en que se publicó desde Enero de & autistic disorder AND oral habits & 14 \\
\hline & 2003 hasta 2013 & intellectual disability AND craniofacial & 4 \\
\hline & Tipo de publicación: Todos & abnormalities & \\
\hline & Tipo de documentos: Todos & intellectual disability AND malocclusion & 37 \\
\hline & & intellectual disability AND oral habits & 35 \\
\hline \multirow[t]{6}{*}{ LiLACS } & $\begin{array}{l}\text { Idioma de la interfase: } \\
\text { español, inglés }\end{array}$ & $\begin{array}{l}\text { autistic disorder AND craniofacial } \\
\text { abnormalities }\end{array}$ & 0 \\
\hline & & autistic disorder AND malocclusion & 1 \\
\hline & & autistic disorder AND oral habits & 0 \\
\hline & & $\begin{array}{l}\text { intellectual disability AND craniofacial } \\
\text { abnormalities }\end{array}$ & 4 \\
\hline & & intellectual disability AND malocclusion & 2 \\
\hline & & intellectual disability AND oral habits & 0 \\
\hline \multirow[t]{6}{*}{ Science Direct } & $\begin{array}{l}\text { All sources (todas las fuentes), all fields } \\
\text { (todos los campos) }\end{array}$ & $\begin{array}{l}\text { autistic disorder AND craniofacial } \\
\text { abnormalities }\end{array}$ & 262 \\
\hline & Subject: Medicine and Dentistry & autistic disorder AND malocclusion & 31 \\
\hline & Date range: 2003 to present & autistic disorder AND oral habits & 202 \\
\hline & & $\begin{array}{l}\text { intellectual disability AND craniofacial } \\
\text { abnormalities }\end{array}$ & 363 \\
\hline & & intellectual disability AND maloclussion & 68 \\
\hline & & intellectual disability AND oral habits & 357 \\
\hline
\end{tabular}




\begin{tabular}{|c|c|c|c|}
\hline Base de datos & Parámetros de búsqueda & Términos de búsqueda & Resultado \\
\hline \multirow[t]{7}{*}{ EMBASE } & Publications from: 2003 to 2013 & autistic disorder AND craniofacial & 22 \\
\hline & Combine: using And & abnormalities & \\
\hline & Records from: Embase & autistic disorder AND malocclusion & 5 \\
\hline & Quick limits: Humans, with abstract & autistic disorder AND oral habits & 2 \\
\hline & $\begin{array}{l}\text { Areas of focus: Anatomy and } \\
\text { development, pediatrics. }\end{array}$ & $\begin{array}{l}\text { intellectual disability AND craniofacial } \\
\text { abnormalities }\end{array}$ & 145 \\
\hline & Article languages: English, Spanish & intellectual disability AND maloclussion & 21 \\
\hline & $\begin{array}{l}\text { Age groups: Preschool child: } 1 \text { to } 6 \\
\text { years, School child: } 7 \text { to } 12 \text { years, Child: } \\
1 \text { to } 12 \text { years, Adolescent: } 13 \text { to } 17 \\
\text { years }\end{array}$ & intellectual disability AND oral habits & 5 \\
\hline \multirow[t]{7}{*}{ OVID } & $\begin{array}{l}\text { Grupo de recursos: Ciencias biomédicas } \\
\text { y Todos los recursos }\end{array}$ & $\begin{array}{l}\text { autistic disorder AND craniofacial } \\
\text { abnormalities }\end{array}$ & 16 \\
\hline & Límites: Abstractas, Diagnosis, Full & autistic disorder AND malocclusion & 21 \\
\hline & Systematic Reviews, Humans, Spanish, & autistic disorder AND oral habits & 16 \\
\hline & $\begin{array}{l}\text { Evidence-Based Medicine Reviews, Full } \\
\text { Text, English Language }\end{array}$ & $\begin{array}{l}\text { intellectual disability AND craniofacial } \\
\text { abnormalities }\end{array}$ & 6 \\
\hline & Publication year: 2003 - 2013 & intellectual disability AND maloclussion & 16 \\
\hline & $\begin{array}{l}\text { Age groups: All Child ( } 0 \text { to } 18 \text { years), } \\
\text { Preschool Child ( } 2 \text { to } 5 \text { years),Child ( } 6 \text { to } \\
12 \text { years), Adolescent ( } 13 \text { to } 18 \text { years }\end{array}$ & intellectual disability AND oral habits & 6 \\
\hline & & TOTAL & 1763 \\
\hline
\end{tabular}

TABLA 2

ARTículos SELECCIONADOS PARA LECTURA DEL RESUMEN

\begin{tabular}{|c|c|c|c|}
\hline Autores & Título del artículo & Revista & Publicación \\
\hline Murray y cols. (33) & $\begin{array}{l}\text { A review of attention-deficit/hyperactivity } \\
\text { disorder from the dental perspective }\end{array}$ & $\begin{array}{l}\text { The New Zealand Dental } \\
\text { Journal }\end{array}$ & 2012 \\
\hline Winter y cols. (34) & $\begin{array}{l}\text { A review of malocclusion among individuals with } \\
\text { mental and physical disabilities }\end{array}$ & Special Care in Dentistry & 2008 \\
\hline $\begin{array}{l}\text { Nagendra y } \\
\text { Jayachandra (18) }\end{array}$ & $\begin{array}{l}\text { Autism spectrum disorders: dental treatment } \\
\text { considerations }\end{array}$ & $\begin{array}{l}\text { Journal of International } \\
\text { Dental and Medical } \\
\text { Research }\end{array}$ & 2012 \\
\hline $\begin{array}{l}\text { Zafeiriou y cols. } \\
\text { (35) }\end{array}$ & Childhood autism and associated comorbidities & Brain and Development & 2007 \\
\hline Lu y cols. (36) & $\begin{array}{l}\text { Dental health }- \text { a challenging problem for a } \\
\text { patient with autism spectrum disorder }\end{array}$ & $\begin{array}{l}\text { General Hospital } \\
\text { Psychiatry }\end{array}$ & 2013 \\
\hline Salles y cols. (37) & $\begin{array}{l}\text { Dental needs and management of children with } \\
\text { special health care needs according to type of } \\
\text { disability }\end{array}$ & $\begin{array}{l}\text { Journal of Dentistry for } \\
\text { Children }\end{array}$ & 2012 \\
\hline $\begin{array}{l}\text { DeMattei y cols. } \\
\text { (38) }\end{array}$ & $\begin{array}{l}\text { Oral assessment of children with an autism } \\
\text { spectrum disorder }\end{array}$ & Journal of Dental Hygiene & 2007 \\
\hline $\begin{array}{l}\text { Anders y Davis } \\
\text { (39) }\end{array}$ & $\begin{array}{l}\text { Oral health of patients with intellectual } \\
\text { disabilities: a systematic review }\end{array}$ & Special Care in Dentistry & 2010 \\
\hline $\begin{array}{l}\text { Vishnu Rekha y } \\
\text { cols. (40) }\end{array}$ & $\begin{array}{l}\text { Oral health status of children with autistic } \\
\text { disorder in Chennai }\end{array}$ & $\begin{array}{l}\text { European Archives of } \\
\text { Paediatric Dentistry }\end{array}$ & 2012 \\
\hline $\begin{array}{l}\text { Luppanapornlarp } \\
\text { y cols. }(41)\end{array}$ & $\begin{array}{l}\text { Periodontal status and orthodontic treatment } \\
\text { need of autistic children }\end{array}$ & $\begin{array}{l}\text { World Journal of } \\
\text { Orthodontics }\end{array}$ & 2010 \\
\hline
\end{tabular}




\begin{tabular}{lllc}
\hline \multicolumn{1}{c}{ Autores } & \multicolumn{1}{c}{ Título del artículo } & \multicolumn{1}{c}{ Revista } & Publicación \\
\hline $\begin{array}{l}\text { de Oliveira y cols. } \\
\text { (42) }\end{array}$ & $\begin{array}{l}\text { Prevalence and determinant factors of } \\
\text { malocclusion in children with special needs }\end{array}$ & $\begin{array}{l}\text { European Journal of } \\
\text { Orthodontics }\end{array}$ & 2011 \\
$\begin{array}{l}\text { Gallagher y Fiske } \\
\text { (43) }\end{array}$ & Special care dentistry: a professional challenge & British Dental Journal & 2007 \\
Gurbuz y cols. (27) & $\begin{array}{l}\text { The prevalence of temporomandibular disorder } \\
\text { signs in people with mental retardation }\end{array}$ & $\begin{array}{l}\text { Journal of Oral } \\
\text { Rehabilitation }\end{array}$ & 2010 \\
\hline
\end{tabular}

Al evaluar la información de los estudios seleccionados se encontró que no había datos suficientes para el propósito de la presente revisión sistemática. No obstante, dichas investigaciones presentaron otras características en el grupo de pacientes con discapacidad física o mental con base en: a) los criterios de la clasificación de maloclusión de Angle, de 1899, método en el que se clasifican las maloclusiones como clase I, II (división 1 o 2) o clase III. b) El Î́ndice de Estética Dental (DAl) utilizado por la Organización Mundial de la Salud, que se basa en estándares de estética definidos socialmente para clasificar una maloclusión. Este índice utiliza 10 componentes clínicos y estéticos que ponderados dan un puntaje final DAl. c) El Índice de Necesidad de Tratamiento Ortodóntico (IOTN), de Brook y Shaw, de 1989, que mide el componente de salud dental separado del componente estético. Cada componente tiene 5 grados que van desde el 1 (sin necesidad de tratamiento) hasta el 5 (con necesidad de tratamiento). d) La condición oral presente que incluye presencia de placa bacteriana, gingivitis, caries, restauraciones, bruxismo, maloclusión, retraso en la erupción o dientes perdidos, anomalías del desarrollo, fluido salival, lesiones y la capacidad de respuesta de defensa en la cavidad oral.

\section{Diseño de los estudios}

El diseño de los estudios seleccionados fue de tipo no experimental. Uno de ellos fue una revisión sistemática de la literatura (Winter y colaboradores [34]), dos fueron estudios de tipo observacional (DeMattei y colaboradores [38]; Luppanapornlarp y colaboradores [41]) y el cuarto consistió en un estudio de corte transversal (Vishnu Rekha y colaboradores [40]).

\section{Participantes de los estudios}

El tamaño de la muestra de los estudios escogidos fue diferente. El estudio de DeMattei y colaboradores contó con la participación de 55 niños (40 niños y 15 niñas), de los cuales 39 tuvieron diagnóstico de trastorno autista y 16 se diagnosticaron con otro trastorno del desarrollo. Las edades oscilaban entre los 2,6 y los 21 años (38). Vishnu Rekha y colaboradores
(40) incluyeron una población de 483 niños (363 niños y 120 niñas) con diagnóstico clínico de autismo, con edades entre los 4 y 16 años. La muestra se dividió en 3 grupos de acuerdo con la dentición: dentición temporal, dentición mixta y dentición permanente. Por su parte, el artículo de Luppanapornlarp y colaboradores (41) contó con una muestra de 80 niños, de los cuales 32 eran autistas y 48 sanos. La edad de los participantes se encontraba en el rango entre los $8 y$ los 12 años de edad sin distinción de sexo. El estudio de Winter y colaboradores (34) incluyó pacientes con discapacidad mental y física sin limitación por grupos de edad o sexo. En ese estudio se reportaron participantes con varios tipos de discapacidades como síndrome de Down, parálisis cerebral, trastornos de hendiduras, discapacidad mental y discapacidades físicas (anexo).

\section{Características de pacientes con retardo mental}

Ninguno de los cuatro estudios seleccionados reportan características de pacientes con RM. Cabe mencionar que Winter y colaboradores (34), en su revisión sistemática de la literatura, hacen referencia a la presencia de maloclusión en "discapacitados mentales". Mencionan que la prevalencia reportada entre las personas con discapacidad varía entre el $27 \%$ y el 58 $\%$, en quienes tenían una discapacidad visual, y de un $82 \%$ a un $97 \%$ en personas con síndrome de Down. Las personas con parálisis cerebral tuvieron el segundo lugar más alto de prevalencia de maloclusiones (59-92\%), seguidas quienes tenían discapacidades mentales (54-84\%). Las personas sin discapacidad tenían la menor prevalencia de maloclusión, entre un $22 \%$ y un $50 \%$ (anexo).

\section{Características de pacientes con autismo}

Ninguno de los cuatro estudios seleccionados reportan características de pacientes con autismo. Sin embargo, DeMattei y colaboradores (38) compararon un grupo de 39 niños con trastorno del espectro autista (TEA) con uno de 16 niños con otros trastornos del desarrollo (TD), en edades entre 2,6 y 5 años y entre 
9 y 21 años. Encontraron que los niños más pequeños con TEA que vivían con sus padres o representantes manifestaron más signos clínicos de bruxismo. Al comparar los niños con TEA con los que tenían otros TD, los últimos mostraron significativamente más lesiones orales que involucraban dientes, mejillas, labios, lengua o encía, fluido salival anormal (excesivo) y anomalías del desarrollo. Asimismo, reportaron presencia de maloclusión clase I (46,2 \%), clase II (35,9 $\%)$ y clase III (17,9\%), apiñamiento dental (12,8 \%) y mordida cruzada (2,6 \%).

Por otra parte, Vishnu Rekha y colaboradores (40) compararon un grupo de niños $(n=363)$ con uno de niñas $(n=120)$ entre 4 y 16 años de edad con diagnóstico de autismo. Dentro de las características evaluadas estuvieron la maloclusión -específicamente la presencia de apiñamiento, inclinación labioaxial aumentada de los dientes anteriores (que se consideró proinclinación, mordida abierta anterior) si los dientes anteriores superiores no ocluyen con los inferiores, y rotaciones-, las anomalías del desarrollo y las alteraciones orales. Estos autores encontraron que la proporción de niños y niñas con maloclusiones fue diferente según el tipo de dentición. En dentición temporal, la proporción fue igual ( $p$ $=0,371)$ y diferente en dentición mixta y permanente $(p=0,000)$. Este hallazgo fue significativamente mayor en los niños (anexo).

\section{Relación causa-efecto de los hábitos orales y características craneofaciales del retardo mental y autismo}

Ninguno de los cuatro estudios seleccionados reporta una relación causa-efecto de los hábitos orales y las características craneofaciales del RM y del autismo. Winter y colaboradores (34), en su revisión sistemática de la literatura, reportan una prevalencia de maloclusiones entre un $54 \%$ y un $84 \%$, en quienes presentaban discapacidades mentales en comparación con los que tenían discapacidad de origen físico. Las maloclusiones clase II y clase III eran comunes en las personas con parálisis cerebral y síndrome de Down, respectivamente. Apiñamientos, diastemas anteriores y relaciones molares anteroposteriores mayores a media cúspide fueron frecuentes entre las personas con discapacidades. Los resultados variaron de acuerdo con la discapacidad, pero se atribuyeron a anomalías musculoesqueléticas, relaciones alteradas de la base de cráneo, erupción dental prematura, cirugía correctiva e incompetencia labial (anexo).

\section{Diferencias de las características craneo- faciales según el grado de severidad del retardo mental y autismo}

Ninguno de los cuatro estudios seleccionados reporta diferencias en las características craneofaciales según el grado de severidad del RM y del autismo. Winter y colaboradores (34), en su revisión sistemática de la literatura, refieren una prevalencia de la maloclusión en personas con discapacidad del $29 \%$ al $92 \%$, en comparación con lo encontrado en los controles del $22-50 \%$ (anexo).

Cambios de las características craneofaciales según la edad en pacientes con retardo mental y autismo

Ninguno de los cuatro estudios seleccionados reporta cambios de las características craneofaciales según la edad en pacientes con RM y autismo. DeMattei y colaboradores (38) encontraron que el grupo de los niños más pequeños (2,6 a 5 años) mostró más signos clínicos de bruxismo que el grupo de niños mayores (entre 9 y 21 años). Vishnu Rekha y colaboradores (40) reportaron que los niños autistas con dentición permanente tenían significativamente más maloclusión que los que tenían dentición temporal o mixta (anexo).

\section{Tipo de evidencia}

El tipo de evidencia en cada estudio se clasificó de acuerdo con la Agencia para la Investigación y Calidad de la Salud de Estados Unidos. Todos los estudios contaron con un tipo de evidencia 3, por tratarse de estudios descriptivos no experimentales bien diseñados. Los estudios de DeMattei y colaboradores (38), Vishnu Rekha y colaboradores (40) y Luppanapornlarp y colaboradores (41) tienen un grado de recomendación $B$, lo que significa que es favorable. El estudio de Winter y colaboradores (34), por su parte, tiene un grado de recomendación $\mathrm{A}$, lo que significa que es extremadamente recomendable. Esta información apoya que las metodologías empleadas y los hallazgos reportados en los estudios referidos se pueden tomar como base para la toma de decisiones clínicas en un grupo de pacientes con necesidades especiales como RM o autismo (anexo).

\section{Limitaciones del estudio}

La presente investigación consistió en una búsqueda sistemática para indagar qué características craneofaciales se encontraban reportadas en la literatura en poblaciones de pacientes con RM y autismo, sin considerar dentro de las variables el estado de salud oral ni el manejo del comportamiento durante la consulta 
odontológica. Los resultados de las búsquedas pudieron verse afectados tanto por el periodo analizado como por los idiomas, ya que podrían existir estudios en idiomas diferentes a inglés y español, publicados antes del 2003. Además, pudo incidir la forma cómo se analizaron y presentaron los resultados, dado que no todas las investigaciones reportaron sus hallazgos con valores estadísticos y se limitaron a la descripción de las observaciones. Debido a la falta de información obtenida de los artículos en relación con los objetivos de la presente revisión, los datos no se procesaron con ayuda del software RevMan 5, por lo cual no se determinó estadísticamente la heterogeneidad de los resultados. Los de esta revisión están sujetos al número limitado de estudios incluidos, que no permitió ni análisis ni comparaciones estadísticas, hecho que dificulta generalizar los resultados.

\section{DISCUSIÓN}

La búsqueda sistemática produjo cuatro estudios relacionados con las características craneofaciales de pacientes con necesidades especiales. Los resúmenes de estos estudios mostraron que la base de la literatura existente está bien descrita; pero, así mismo, es limitada con respecto al alcance y la calidad de estudios encontrados relacionados. En cuanto al objetivo principal de este trabajo, para avanzar en el abordaje multidisciplinario de pacientes con necesidades especiales basado en la evidencia, ninguno de los estudios revisados presenta una descripción completa de las características craneofaciales de estos pacientes. En su mayoría, las investigaciones revisadas se limitan a la descripción y al reporte de hallazgos clínicos en la cavidad oral. Ello sugiere que esta población puede ser tratada desde los diferentes campos de la odontología por medio de enfoques que utilizan intervenciones dentales y comportamentales. Sin embargo, es claro que la discapacidad en sí complica la investigación clínica. Las publicaciones existentes informan datos de varias poblaciones con discapacidad, pero no se pueden generalizar los resultados a los distintos subgrupos, debido a la naturaleza heterogénea de la población.

Los estudios que se tuvieron en cuenta para el análisis en la presente revisión reportan características encontradas en el grupo de pacientes con discapacidad física o mental y en su mayoría coinciden en evaluar los criterios de la clasificación de maloclusión de Angle, el DAl, el IOTN, la condición oral presente o el Índice Periodontal Comunitario de Necesidad de Tratamiento (CPITN). Las medidas clínicas de malo- clusión, como la clasificación de Angle, el DAl y el IOTN, se usaron y ajustaron a las necesidades de la población de los diferentes estudios reportados. La variabilidad entre los examinadores dentro de cada estudio y en comparación con otras investigaciones incluidas en la presente investigación genera sesgos sobre los hallazgos y permite sacar diferentes conclusiones que dependen del entrenamiento y el conocimiento del clínico. A esto se suma que gran parte de la literatura revisada no reporta datos estadísticos de los hallazgos en la población de estudio; por lo tanto, la comparación entre varios índices puede ser limitada, lo que hace difícil escalar de un índice a otro (como se hizo en el estudio de Winter y colaboradores [34], con el DAl y el IOTN). La alta variabilidad y baja confiabilidad de estos índices presenta la posibilidad de resultados contradictorios.

Algunos estudios reportan que la maloclusión varía de acuerdo con el origen físico o mental de la discapacidad $(34,44)$. Winter y colaboradores (34) sugieren una mayor prevalencia de maloclusión en quienes presentan una discapacidad mental cuando se comparan con los que tienen limitaciones de tipo visual o auditivo; asimismo, una mayor prevalencia de la maloclusión en pacientes con discapacidades (29-92 \%) al compararlos con la población general (22-50 $\%)$. Estos datos son consistentes con los reportados por Brown y Schodel (3), quienes encontraron una mayor prevalencia de la maloclusión en personas con discapacidad (48 \% a 86 \%) en comparación con la población general. Aunque la prevalencia de la maloclusión fue alta en los pacientes con algún tipo de discapacidad, al ser comparada con los controles, ninguna diferencia fue estadísticamente significativa.

La distribución de la maloclusión de acuerdo con la clasificación de Angle no fue diferente en una población con discapacidad mental en comparación con los controles (con excepción del síndrome de Down) (3). Los resultados reportados por Utomi y Onyeaso (7) indican que en niños con discapacidad mental hubo una mayor prevalencia de relación molar de clase I (68 \%) y maloclusión clase II en un menor porcentaje (31 \%). Sin embargo, Winter y colaboradores (34) encontraron que en personas con discapacidad hubo una alta prevalencia de maloclusión clase II (55,8 \%) y un bajo porcentaje tuvo maloclusión clase III (1,9 \%). Estos resultados se atribuyeron a la erupción temprana de los dientes temporales, la posición baja de la lengua y de la cabeza y a la incompetencia labial relacionada con una alteración en el músculo orbicular (en el labio superior) como respuesta a la 
sobremordida horizontal excesiva. Vigild (5) también reportó que en personas con RM hubo una mayor prevalencia de maloclusión clase II (28\%) frente a la maloclusión clase III (17\%).

Estudios realizados en niños autistas reportaron una mayor tendencia a la maloclusión clase II (63 \%) en comparación con los controles $(52 \%)(40,45)$. Aunque se encontraron diferencias entre el grupo de autistas y el grupo control, la razón de momios (odds ratio, en inglés) fue de $0,69(0,27$ a 1,77$)$, con un intervalo de confianza correspondiente al $95 \%$. Ello indica que la diferencia entre los dos grupos no fue significativa (44). Estos hallazgos fueron similares a los reportados por DeMattei y colaboradores (38), quienes encontraron que un $54 \%$ de los niños tenía maloclusión, de los cuales un $36 \%$ presentaba maloclusión clase II y un $18 \%$ clase III. A pesar de encontrarse diferencias entre los grupos, ninguna fue estadísticamente significativa (40).

Otros signos de maloclusión reportados fueron dientes perdidos (8\%, Utomi y Onyeaso), espaciamiento o diastemas (59\%, Utomi y Onyeaso), sobremordida horizontal aumentada (14 \%, Utomi y Onyeaso; 19 $\%$, Onyeaso; $27 \%$, Vigild), mordida abierta (25,5\%, Utomi y Onyeaso; $23 \%$, Vigild), mordida cruzada anterior (2,6 \%, DeMattei y colaboradores; $29 \%$, Vigild) y apiñamiento (60 \%, Tandon y colaboradores; $13 \%$, DeMattei y colaboradores; $28 \%$, Utomi y Onyeaso) $(5,7,31,38,40,45)$. Resultados similares fueron reportados por Oliveira y colaboradores (42), quienes encontraron en una población con discapacidad física y mental (síndrome de Down y parálisis cerebral) una prevalencia considerable de mordida cruzada anterior $(20,4 \%)$, mordida cruzada posterior $(21,5 \%)$ y mordida abierta anterior (29,8 \%). Ello puede explicarse por la presencia de hábitos de succión no nutritivos que facilitan la aparición de maloclusiones como obstrucción nasal o de la faringe y otros problemas como hipotonía, obesidad y resequedad de las membranas mucosas. La lengua hipotónica y protrusiva, junto con la incompetencia labial, favorece el desarrollo de la mordida abierta anterior y el mantenimiento del hábito de interposición lingual (42).

Estos hallazgos coinciden con los reportados por Desai y colaboradores (44) y Utomi y Onyeaso (7), quienes añaden que las altas frecuencias de anomalías del sector anterior se explican por anomalías funcionales de la lengua y un desarrollo muscular general insuficiente. Por esta razón, se afirma que la maloclusión puede complicar la discapacidad del niño y resultar en trauma dental, enfermedad periodontal (promovida por el apiñamiento y problemas de erupción), problemas funcionales (como masticación o deglución), alteraciones del lenguaje y trastornos temporomandibulares (44). Desde el punto de vista ortodóntico, esto constituye la base etiológica para las alteraciones dentoalveolares o esqueléticas (42), aunque Winter y colaboradores (34) reportaron que no había asociación entre el nivel de función y la maloclusión o la necesidad del tratamiento ortodóntico.

La prevalencia de bruxismo en niños con discapacidad mental fue descrita en el estudio de DeMattei y colaboradores, quienes reportan que en una población de niños con autismo comparados con niños con otros trastornos del desarrollo, un $44 \%$ tenía signos clínicos de bruxismo y solo un $5 \%$ tenía retraso en la erupción o dientes perdidos. Estos autores mostraron que, con excepción del bruxismo y la gingivitis, no se encontraron diferencias significativas en el estado de salud oral de los niños con autismo cuando se compararon niños pequeños (2,6-5 años), mayores (9-21 años), o niños con autismo que vivían con sus padres o acudientes, con quienes vivían en residencias escolares. Reportaron además que los niños pequeños que vivían con sus padres manifestaron más signos clínicos de bruxismo, $\chi^{2}(1 ; n=39)=6,88, p<0,01$, que los niños de las residencias escolares. Debido a que algunos mayores (9-21 años) con autismo mostraron signos de bruxismo, la edad más que el autismo puede ser el factor asociado con el bruxismo. Los mismos autores reportaron también que los niños diagnosticados con otros trastornos del desarrollo mostraron significativamente más lesiones orales ( $p<0,01$ ), anomalías del desarrollo $(p=0,02)$ y flujo salival anormal $(p=0,00)$ que los niños diagnosticados con autismo (38).

Aunque en la presente revisión sistemática no se consideró analizar la información relacionada con las condiciones orales presentes en los pacientes con discapacidad, se encontró que existe una alta prevalencia de mala higiene oral y caries dental que puede conducir a la pérdida prematura de los dientes y posteriormente al desarrollo de maloclusiones. Desai y colaboradores (44) también reportaron tasas de caries dental mayores en una población de niños con discapacidades (92\%) relacionadas con factores como medicación, dieta e higiene oral deficiente. Factores locales como maloclusión, pérdida de las funciones masticatorias normales y atrición debida al bruxismo fueron más frecuentes en quienes tenían discapacidades severas. Vishnu Rekha y colaboradores (40) no encontraron diferencias significativas en el 
estado de salud oral de niños autistas al compararlos, según el tipo de dentición, temporal, mixta y permanente. Los niños con dentición permanente mostraron más gingivitis y maloclusión que los niños en dentición temporal o mixta. Igualmente, estos autores también reportaron que los niños con autismo presentaron mala higiene oral, alta tasa de enfermedades periodontales y riesgo alto de caries dental, resultados que coinciden con Lowe y colaboradores (29), Onyeaso (45) y Friedlander y colaboradores (28), quienes afirman que los pacientes autistas presentan un mayor índice de caries en dentición temporal. Contrario a lo anterior, Shapira y colaboradores (32), Loo y colaboradores (30), Vajawat y Deepika (46), Jaber (17) y DeMattei y colaboradores (38) encontraron menores tasas de caries, pero mayores problemas periodontales, lo cual puede explicarse por la supervisión o realización de la higiene oral por parte de los padres o cuidadores durante las actividades de la vida diaria del niño y la baja dieta cariogénica.

Otros autores mencionan que un factor para tener en cuenta como posible agravante del mal estado de salud oral de los pacientes con necesidades especiales es el relacionado con sus comportamientos/ factores de vida. En estos pacientes prevalecen la dieta blanda y dulce, la capacidad masticatoria disminuida, el consumo de alimentos de paquete y la higiene oral deficiente, asociada a hábitos irregulares de cepillado debidos a las dificultades de los niños (como la falta de destreza manual) o de sus padres/ cuidadores, para realizar una buena higiene oral (16). Debido a lo anterior, se requiere un cepillado dental frecuente y exhaustivo que permita controlar los factores asociados con la mala higiene oral de estos pacientes $(17,28,31,46)$. A los problemas descritos se suma el consumo, en algunos niños, de medicamentos antipsicóticos, antidepresivos y anticonvulsivantes prescritos para disminuir la irritabilidad, la ansiedad, las conductas autolesivas, la agresividad, las conductas repetitivas, los delirios y las alucinaciones. Hay efectos adversos generales como xerostomía, factor de riesgo para el aumento de caries $(17,28,31,44,46)$.

En conjunto, los resultados de la presente revisión mostraron que los niños diagnosticados con RM y autismo tienen una prevalencia considerable de maloclusión y bruxismo en comparación con los controles. Estos síntomas pueden estar relacionados con la conducta alterada de los pacientes, como succión digital, onicofagia o cuerpos extraños, autodaño o autoextracción de dientes $(34,38,40,41,46)$.

\section{CONCLUSIONES}

No se encontró evidencia disponible sobre características craneofaciales propias de una población con necesidades especiales, especialmente en RM y autismo.

En pacientes con discapacidad mental y autismo, las anomalías dentofaciales más frecuentemente reportadas son la maloclusión y el bruxismo sin distinción de edad o género.

No se pudo determinar si existe una relación causaefecto entre hábitos orales y las características craneofaciales de los pacientes con RM y autismo.

Los datos reportados por la literatura no permitieron identificar diferencias en las características craneofaciales de acuerdo con la gravedad del RM y el autismo.

Debido a la escasez de información, no se pudo identificar si las características craneofaciales de pacientes con RM y autismo cambian de acuerdo con la edad.

\section{RECOMENDACIONES}

Se sugiere realizar más investigación en pacientes con necesidades especiales, con el fin de identificar las características craneofaciales propias de esta población.

En un futuro las nuevas investigaciones deben procurar determinar qué causas de las maloclusiones afectan a los pacientes con discapacidad. De esta forma se podrían determinar cuáles de ellas se pueden prevenir.

\section{REFERENCIAS}

1. Somani R, Sunil MK, Jaidka S, Khaira J. Dentofacial anomalies and oral hygiene status in mentally challenged; a survey. J Indian Acad Oral Med Radiol. 2011; 23(1): 51-3.

2. Bhowate R, Dubey A. Dentofacial changes and oral health status in mentally challenged children. $\mathrm{J}$ Indian Soc Pedod Prev Dent. 2005; 23(2): 71-3.

3. Brown JP, Schodel DR. A review of controlled surveys of dental disease in handicapped persons. ASDC J Dent Child 1976; 43: 313-20.

4. Dinesh RB, Arnitha HM, Munshi AK. Malocclusion and orthodontic treatment need of handicapped individuals in South Canara, India. Int Dent J. 2003; 53: 13-8.

5. Vigild M. Prevalence of malocclusion in mentally retarded young adults. Community Dent Oral Epidemiol. $1985 ; 13 ; 183-4$. 
6. Atmetlla G, Burgos V, Carrillo A, Chaskel R. Behavior and orofacial characteristics of children with attentiondeficit hyperactivity disorder during a dental visit. J Clin Pediatr Dent. 2006; 30(3): 183-9.

7. Utomi IL, Onyeaso CO. Malocclusion and orthodontic treatment need of mentally handicapped children in Lagos, Nigeria. Pesq Bras Odontopediatr Clin Integr. 2009; 9(1): 7-11.

8. American Psychiatric Association. Diagnostic and statistical manual of mental disorders, DSM IV. 4th edition. Washington DC: American Psychiatric Association; 1994.

9. Rodríguez M. Autismo: un síndrome de disfunción neurológica [monografía]. Consultado: abril del 2013. Disponible en http://www.monografias.com/trabajos12/ autis/autis.shtml.

10. Barthélémy C, Fuentes J, Howlin P, van der Gaag R. Persons with autism spectrum disorders: identification, understanding, intervention [internet]. Brussels, Belgium: Autism-Europe AISLAB; 2007. Disponible en: http://www.autismeurope.org/files/files/persons-withautism-spectrum-disorders-identification-understanding-intervention.pdf.

11. Instituto Nacional de Trastornos Neurológicos y Accidentes Cerebrovasculares(NINDS). Autismo [monografía] [internet]. Bethesda, MD: NINDS, National Institutes of Health; 2012 [Citado ago 2012]. Disponible en: http://espanol.ninds.nih.gov/trastornos/autismo.htm.

12. Tripi G, Roux S, Canziani T, Bonnet Brilhault F, Barthélémy C, Canziani F. Minor physical anomalies in children with autism spectrum disorder. Early Human Dev. 2008; 84(4): 217-23.

13. Waldrop MF, Pederson FA, Bell RQ. Minor physical anomalies and behaviour in preschool children. Child Dev. 1968; 39: 391-400.

14. Roland PS, Smith TL, Schwartz SR, Rosenfeld RM, Ballachanda B, Earll JM, Fayad J, Harlor AD Jr, Hirsch BE, Jones SS, Krouse HJ, Magit A, Nelson C, Stutz DR, Wetmore S. Clinical practice guideline: cerumen impaction. Otolaryngol Head Neck Surg. 2008 Sep; 139(3 Suppl 2): S1-S21.

15. Millá MG, Mulas F. Atención temprana y programas de intervención específica en el trastorno del espectro autista. Rev Neurol. 2009; 48: S47-S52.

16. González J, Guedez K, Carrillo GA, Chaskel R. Comportamiento y características orofaciales en niños con déficit de atención e hiperactividad durante procedimientos no invasivos en odontología [Trabajo de grado]. Bogotá: Pontificia Universidad Javeriana, Facultad de Odontología; 2007.

17. Jaber MA. Dental caries experience, oral health status and treatment needs of dental patients with autism. J Appl Oral Sci. 2011; 19(3): 212-7.

18. Nagendra J, Jayachandra S. Autism spectrum disorders: dental treatment considerations. J Int Dent Med Res. 2012; 5(2): 118-21.

19. Cheung C, McAlonan GM, Fung YY, Fung G, Yu KK, Tai KS, Sham PC, Chua SE. MRI Study of physical anomaly in childhood autism implicates aberrant neurodevelopment in infancy. PLoS ONE. 2011; 6(6): 1-7.

20. Krouse JP, Kauffman JM. Minor physical anomalies in exceptional children. A review and critique of research. J Abnorm Child Psychol. 1982; 10: 247-64.

21. Krinjarić I, Jukić J, Skrinjarić K, Glavina D, Legović M, Ulovec Z. Dental and minor physical anomalies in children with developmental disorders-a discriminant analysis. Coll Antropol. 2003 Dec; 27(2): 769-78.

22. McKusick VA, Amerger JS. The morbid anatomy of the human genome: chromosomal location of mutations causing disease. J Med Genet. 1994; 3: 265-79.

23. Ulovec ZS, Skrinjaric I, Atovic AC, Ivljak MC, Szirovicza L. Prevalence and significance of minor anomalies in children with impaired development. Acta Paediatr. 2004; 93: 836-40.

24. Campbell M, Geller B, Small AM, Petti TA, Ferris SH. Minor physical anomalies in young psychotic children. Am J Psychiatry. 1978; 135(5): 573-5.

25. Bhattacharyya R, Sanyal D, Roy K, Bhattacharyya S. Correlation between physical anomaly and behavioral abnormalities in Down syndrome. J Ped Neurosc. 2010; 5: $105-10$

26. Gualtieri CT, Adams A, Shen CD, Loiselle D. Minor physical anomalies in alcoholic and schizophrenic adults and hyperactive and autistic children. Am J Psychiatry. 1982; 139: 640-2.

27. Gurbuz O, Kursoglu P, Alatas G, Altinbas K. The prevalence of temporomandibular disorder signs in people with mental retardation. J Oral Rehabil. 2010 Nov; 37(11): 834-9.

28. Friedlander H, Friedlander KI, Velasco Ortega E, Casas Baquero N. Autismo: fisiopatología, atención médica e implicaciones dentales. Arch Odontoestomatol. 2005 May; 21(4): 234-44.

29. Lowe O, Lindermann R. Assessment of the autistic patient's dental needs and ability to undergo dental examination. ASDC J Dent Child. 1985; 52: 29-35.

30. Loo CY, Graham RM, Hughes CV. The caries experience and behavior of dental patients with autism spectrum disorder. J Am Dent Assoc. 2008; 139(11): 1518-24.

31. Tandon P, Jha S, Tandon R, Sondhi D, Chandra M, Trivedi JK. Oro-dental pattern in mentally retarded. Indian J Psychiatry. 1990 Apr; 32(2): 185-7.

32. Shapira J, Mann J, Tamari I, Mester R, Knobler H, Yoeli Y, Newbrun E. Oral health status and dental needs of and autistic population of children and young adults. Spec Care dentist. 1989 Mar-Apr; 9(2): 38-41.

33. Murray CM, Naysmith KE, Liu CC, Drummond BK. A review of attention-deficit/hyperactivity disorder from the dental perspective. N Z Dent J. 2012 Sep; 108(3): 95-101.

34. Winter K, Baccaglini L, Tomar S. A review of malocclusion among individuals with mental and physical disabilities. Spec Care in Dentist. 2008 Jan-Feb; 28(1): 19-26.

35. Zafeiriou DI, Ververi A, Vargiami E. Childhood autism and associated comorbidities. Brain Dev. 2007 Jun; 29(5): 257-72. 
36. Lu YY, Wei IH, Huang CC. Dental health-a challenging problem for a patient with autism spectrum disorder. Gen Hosp Psychiatry. 2013 Mar-Apr; 35(2): 214.e1-3.

37. Salles PS, Tannure PN, Oliveira CA, Souza IP, Portela MB, Castro GF. Dental needs and management of children with special health care needs according to type of disability. J Dent Child. 2012 Sep-Dec; 79(3): 165-9.

38. DeMattei R, Cuvo A, Maurizio S. Oral assessment of children with an autism spectrum disorder. J Dent Hyg. 2007; 81(3): 65-75.

39. Anders PL, Davis EL. Oral health of patients with intellectual disabilities: A systematic review. Spec Care Dentist. 2010 May-Jun; 30(3): 110-7.

40. Vishnu Rekha C, Arangannal P, Shahed H. Oral health status of children with autistic disorder in Chennai. Eur Arch Paediatr Dent. 2012; 13(3): 126-31.

41. Luppanapornlarp S, Leelataweewud P, Putongkam P, Ketanont S. Periodontal status and orthodontic treatment need of autistic children. World J Orthod. 2010; 11(3): 256-61.

42. Oliveira AC, Paiva SM, Martins MT, Torres CS, Pordeus IA. Prevalence and determinant factors of malocclusion in children with special needs. Eur J Orthod. Aug 2011; 33(4): 413-8.

43. Gallagher JE, Fiske J. Special care dentistry: a professional challenge. Br Dent J. 2007 May; 202(10): 619-29.
44. Desai M, Messer LB, Calache H. A study of the dental treatment needs of children with disabilities in Melbourne, Australia. Aust J Dent. 2001; 46(1): 41-50.

45. Onyeaso CO. Orthodontic treatment need of mentally handicapped children in Ibadan, Nigeria, according to the Dental Aesthetic Index. J Dent Child. 2003; 70: 15963.

46. Vajawat M, Deepika PC. Comparative evaluation of oral hygiene practices and oral health status in autistic and normal individuals. J Int Soc Prevent Communit Dent. 2012; 2(2): 58-63.

\section{CORRESPONDENCIA}

\author{
Carol Renata Erazo Cerón \\ carolrenata@hotmail.com \\ Gloria Ángela Carrillo Estrada \\ angelacarrilloe@yahoo.com \\ Juliana Velosa Porras \\ juliana.velosa@javeriana.edu.co
}


ANEXO

RESUMEN LOS HALLAZGOS REPORTADOS EN LOS ESTUDIOS SELECCIONADOS PARA SU ANÁLISIS

\begin{tabular}{|c|c|c|c|c|c|}
\hline Referencia & $\begin{array}{l}\text { Diseño del } \\
\text { estudio }\end{array}$ & Participantes & $\begin{array}{l}\text { Características en } \\
\text { pacientes con RM }\end{array}$ & $\begin{array}{l}\text { Características } \\
\text { en pacientes con } \\
\text { autismo }\end{array}$ & $\begin{array}{l}\text { Relación causa-efec- } \\
\text { to de hábitos orales } \\
\text { y características } \\
\text { craneofaciales del } \\
\text { RM y autismo }\end{array}$ \\
\hline $\begin{array}{l}\text { A review of ma- } \\
\text { locclusion among } \\
\text { individuals with } \\
\text { mental and physical } \\
\text { disabilities. Winter y } \\
\text { cols. (34) }\end{array}$ & $\begin{array}{l}\text { Revisión } \\
\text { sistemática de } \\
\text { la Literatura }\end{array}$ & $\begin{array}{l}\text { Pacientes con } \\
\text { diferentes tipos } \\
\text { de Discapacidad } \\
\text { Mental y Física (como } \\
\text { síndrome de Down, } \\
\text { parálisis cerebral } \\
\text { [PC], trastornos de } \\
\text { hendiduras, disca- } \\
\text { pacidad Mental [DM] } \\
\text { y discapacidades } \\
\text { físicas) sin limitación } \\
\text { por grupos de edad o } \\
\text { género. }\end{array}$ & $\begin{array}{l}\text { Datos presentados } \\
\text { en “discapacitados } \\
\text { mentales” (MD). Preva- } \\
\text { lencia de maloclusión } \\
\text { entre las personas con } \\
\text { discapacidad varió } \\
\text { de } 27 \% \text { al } 58 \% \text { (con } \\
\text { discapacidad visual) y } \\
\text { un } 82 \text { a } 97 \% \text { en per- } \\
\text { sonas con Síndrome } \\
\text { de Down. Personas } \\
\text { con PC tuvieron el } \\
\text { segundo lugar más } \\
\text { alto de prevalencia de } \\
\text { maloclusiones (59 \% a } \\
92 \% \text { ), seguidas de las } \\
\text { que tenían discapaci- } \\
\text { dades mentales ( } 54 \% \\
\text { a } 84 \% \text { ). } \\
\text { Personas sin dis- } \\
\text { capacidad tenían la } \\
\text { menor prevalencia de } \\
\text { maloclusión ( } 22 \% \text { a } \\
50 \% \text { ). }\end{array}$ & No se reporta & $\begin{array}{l}\text { No se reporta. } \\
\text { Obtienen una prevalen- } \\
\text { cia de maloclusiones } \\
\text { en quienes presentaban } \\
\text { discapacidades menta- } \\
\text { les entre un } 54 \% \text { a } 84 \\
\text { \%, en comparación con } \\
\text { los que tenían discapa- } \\
\text { cidad física. } \\
\text { Las maloclusiones clase } \\
\text { Il y III eran comunes en } \\
\text { las personas con PC } \\
\text { y Síndrome de Down, } \\
\text { respectivamente. El } \\
\text { apiñamiento, diastema } \\
\text { anterior, y relaciones } \\
\text { molares anteroposte- } \\
\text { riores mayores a } 1 / 2 \\
\text { cúspide fueron frecuen- } \\
\text { tes entre las personas } \\
\text { con discapacidades. } \\
\text { Los resultados fueron } \\
\text { atribuidos a anomalías } \\
\text { musculoesqueléticas, } \\
\text { relaciones alteradas } \\
\text { de la base de cráneo, } \\
\text { erupción dental prema- } \\
\text { tura, cirugía correctiva, } \\
\text { e incompetencia labial. } \\
\text { Solo la mordida profun- } \\
\text { da fue más frecuente } \\
\text { en los controles en } \\
\text { comparación con las } \\
\text { personas con discapa- } \\
\text { cidad. }\end{array}$ \\
\hline $\begin{array}{l}\text { Oral Assessment } \\
\text { of Children with an } \\
\text { Autism Spectrum } \\
\text { Disorder. DeMattei } \\
\text { y cols. (38) }\end{array}$ & $\begin{array}{l}\text { Estudio } \\
\text { observacional }\end{array}$ & $\begin{array}{l}\text { Participaron } 55 \text { niños } \\
\text { ( } 40 \text { niños y } 15 \text { niñas): } \\
39 \text { con diagnós- } \\
\text { tico de trastornos } \\
\text { autista (TEA) y } 16 \\
\text { con diagnóstico de } \\
\text { otro trastorno del } \\
\text { desarrollo (TD). }\end{array}$ & No se reporta & $\begin{array}{l}\text { No se reporta } \\
\text { Compararon un grupo } \\
\text { con TEA ( } 39 \text { niños) y } \\
\text { uno con TD (16 niños) } \\
\text { (edades entre } 2,6 \text { a } \\
5 \text { años y entre } 9 \text { a } 21 \\
\text { años) en cuanto a: } \\
\text { placa visible, gingivitis } \\
\text { visible, caries visible, }\end{array}$ & No se reporta \\
\hline
\end{tabular}




\begin{tabular}{|c|c|c|c|c|c|c|}
\hline $\begin{array}{l}\text { Diferencias de las } \\
\text { características } \\
\text { craneofaciales según } \\
\text { el grado de severidad } \\
\text { del RM y autismo }\end{array}$ & $\begin{array}{c}\text { Cambios de } \\
\text { características } \\
\text { craneofaciales según } \\
\text { la edad en pacientes } \\
\text { con RM y autismo }\end{array}$ & Resultados & Conclusiones & $\begin{array}{c}\text { Nivel } \\
\text { de Evi- } \\
\text { dencia }\end{array}$ & $\begin{array}{l}\text { Grado } \\
\text { de } \\
\text { reco- } \\
\text { men- } \\
\text { dación }\end{array}$ & $\begin{array}{c}\text { Riesgo } \\
\text { de sesgo }\end{array}$ \\
\hline $\begin{array}{l}\text { No se reporta } \\
\text { Reportan que la preva- } \\
\text { lencia de la maloclusión } \\
\text { en personas con disca- } \\
\text { pacidad fue del } 29 \text { al } 92 \\
\% \text { en comparación con } \\
\text { los controles que fue del } \\
22 \text { al } 50 \%\end{array}$ & No se reporta & $\begin{array}{l}\text { La prevalencia de } \\
\text { maloclusión entre las } \\
\text { personas con discapa- } \\
\text { cidad varió de un } 27 \% \\
\text { a } 58 \% \text { entre los que } \\
\text { tenían una discapaci- } \\
\text { dad visual y un } 82 \% \text { a } \\
97 \% \text { en personas con } \\
\text { síndrome de Down. El } \\
\text { segundo lugar fue para } \\
\text { quienes tenían PC (59 } \\
\text { a } 92 \% \text { ), seguidas de } \\
\text { las que tenían DM (54 a } \\
84 \% \text { ). Las personas sin } \\
\text { discapacidad tenían la } \\
\text { menor prevalencia de } \\
\text { maloclusión (22 a } 50 \% \text { ). } \\
\text { El rango de maloclusión } \\
\text { entre todos los minus- } \\
\text { válidos discapacitados } \\
\text { fue de un } 29 \text { a } 92 \% \text {, en } \\
\text { comparación con cada } \\
\text { categoría de discapaci- } \\
\text { dad. Este gran rango es } \\
\text { el resultado de la amplia } \\
\text { variedad de poblaciones } \\
\text { con discapacidades } \\
\text { representadas en cada } \\
\text { estudio. La prevalen- } \\
\text { cia de maloclusión } \\
\text { entre los individuos con } \\
\text { discapacidades físicas y } \\
\text { aquellos con discapa- } \\
\text { cidad visual o auditiva } \\
\text { fue similar a la de los } \\
\text { controles sin discapa- } \\
\text { cidad. }\end{array}$ & $\begin{array}{l}\text { La investigación } \\
\text { futura debe dedi- } \\
\text { carse a determinar } \\
\text { exactamente por qué } \\
\text { la maloclusión es alta } \\
\text { entre las personas } \\
\text { con discapacidad. } \\
\text { Hasta el momento, } \\
\text { se sabe que la ma- } \\
\text { loclusión resulta de } \\
\text { múltiples etiologías } \\
\text { complejas. Se debe } \\
\text { tratar de determi- } \\
\text { nar qué causas se } \\
\text { pueden prevenir } \\
\text { para eliminar estas } \\
\text { discrepancias. }\end{array}$ & $3 a$ & A & $\begin{array}{l}\text { Modera- } \\
\text { do riesgo } \\
\text { de sesgo }\end{array}$ \\
\hline No se reporta & $\begin{array}{l}\text { Encontraron que los niños } \\
\text { más pequeños (de } 2,6 \text { a } \\
5 \text { años), mostraron más } \\
\text { signos clínicos de bruxis- } \\
\text { mo que el de los niños } \\
\text { mayores ( } 9 \text { y } 21 \text { años). }\end{array}$ & $\begin{array}{l}\text { Se observa que el } 85 \% \\
\text { de los } 39 \text { participantes } \\
\text { con ADS tenían placa } \\
\text { visible, el } 62 \% \text { tenían } \\
\text { gingivitis visible; } 21 \% \\
\text { tenían caries visibles; } 15 \\
\% \text { tenían tratamiento } \\
\text { restaurativo (sellantes) } \\
\text { que indicaban trata- } \\
\text { miento dental previo; }\end{array}$ & $\begin{array}{l}\text { Debido a las dificul- } \\
\text { tades de obtener una } \\
\text { muestra represen- } \\
\text { tativa de los niños } \\
\text { con ASD, se usó una } \\
\text { muestra por conve- } \\
\text { niencia. }\end{array}$ & $3 b$ & B & $\begin{array}{l}\text { Modera- } \\
\text { do riesgo } \\
\text { de sesgo }\end{array}$ \\
\hline
\end{tabular}




\begin{tabular}{cccccc}
\hline Referencia & Diseño del & Participantes & Características en \\
estudio & pacientes con RM & $\begin{array}{c}\text { Relación causa-efec- } \\
\text { to de hábitos orales } \\
\text { en pacientes con } \\
\text { autismo }\end{array}$ & $\begin{array}{c}\text { y características } \\
\text { craneofaciales del } \\
\text { RM y autismo }\end{array}$ \\
\hline
\end{tabular}

Edad: entre los 2,6 y

restauraciones visibles,

21 años.

signos clínicos de

bruxismo, erupción

retardada, infección

oral, alteraciones del

desarrollo, alteracio-

nes orales, deforma-

ciones orales, tipo de

maloclusión, fluido sa-

lival y la capacidad de

respuesta de defensa a

nivel oral.

Comparación entre a)

los niños con TEA que

viven con sus padres

y los que están en un

internado; b) los niños

con TEA con los que

tenían otro TD sin in-

cluir TEA y c) los niños

con TEA en edades de

2,6 a 5 años y los de 9

a 21 años.

Reportan: Los niños

más pequeños con

TEA que vivían con sus

padres o represen-

tantes manifestaron

más signos clínicos

de bruxismo. Los

niños mayores que

vivían en un internado

mostraron significati-

vamente más gingivitis.

Al comparar los niños

con TEA con los que

tenían otros TD, éste

último grupo mostró

significativamente más

lesiones orales, fluido

salival anormal y ano-

malías del desarrollo.

Los niños con TEA

mostraron: placa

bacteriana ( $85 \%$ ), gin-

givitis $(62 \%)$ y caries

dental (21\%). 


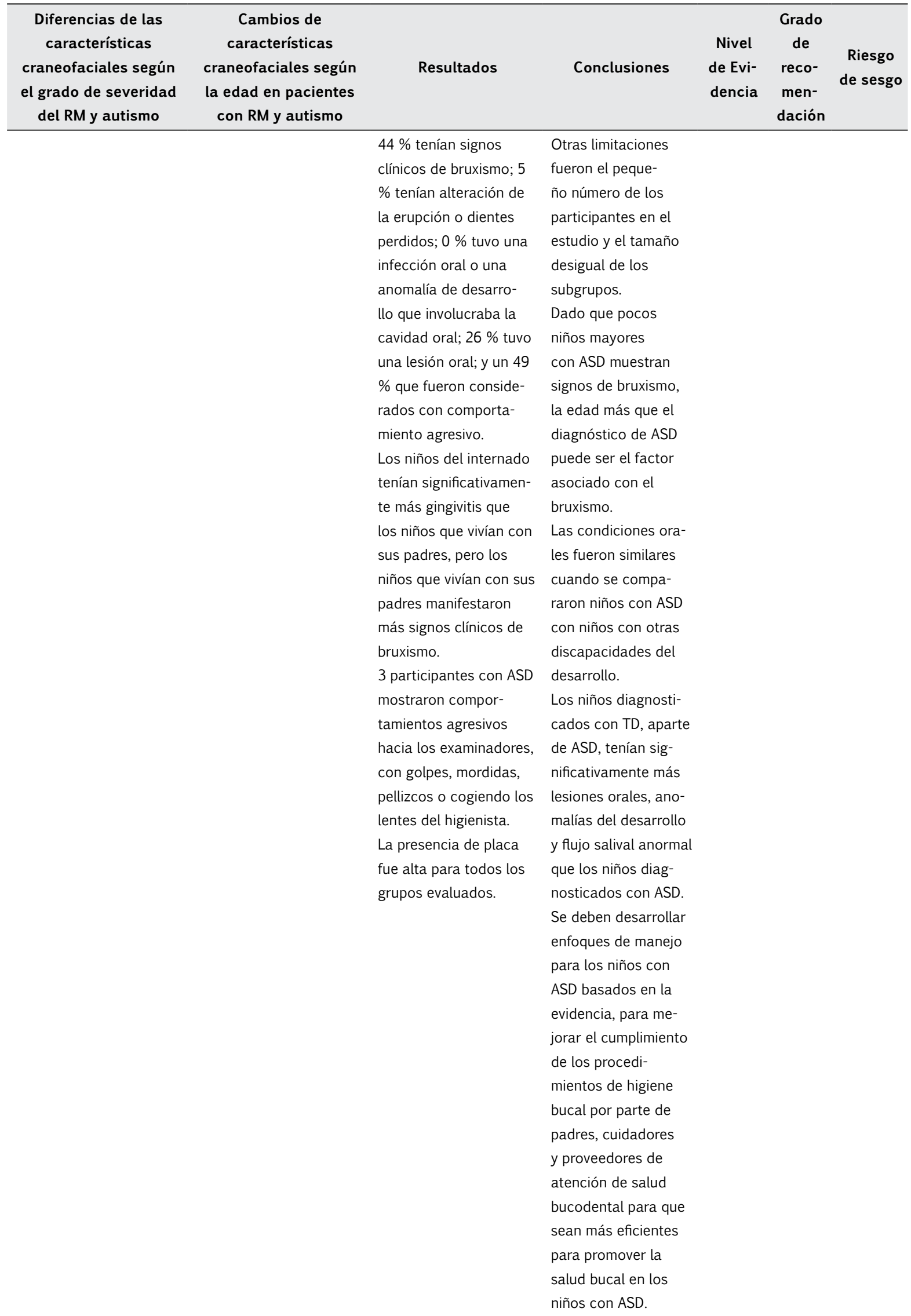




\begin{tabular}{|c|c|c|c|c|c|}
\hline Referencia & $\begin{array}{l}\text { Diseño del } \\
\text { estudio }\end{array}$ & Participantes & $\begin{array}{l}\text { Características en } \\
\text { pacientes con RM }\end{array}$ & $\begin{array}{l}\text { Características } \\
\text { en pacientes con } \\
\text { autismo }\end{array}$ & $\begin{array}{l}\text { Relación causa-efec- } \\
\text { to de hábitos orales } \\
\text { y características } \\
\text { craneofaciales del } \\
\text { RM y autismo }\end{array}$ \\
\hline & & & & $\begin{array}{l}\text { Aproximadamente la } \\
\text { mitad de los niños } \\
\text { con TEA tenían buena } \\
\text { capacidad de defensa } \\
\text { oral. } \\
\text { Encontraron presencia } \\
\text { de maloclusión clase I } \\
(46,2 \%) \text {, clase II (35,9 } \\
\%) \text { y clase III (17,9\%), } \\
\text { apiñamiento dental } \\
(12,8 \%) \text { y mordida } \\
\text { cruzada (2,6 \%). }\end{array}$ & \\
\hline $\begin{array}{l}\text { Oral health status } \\
\text { of children with } \\
\text { autistic disorder } \\
\text { in Chennai. Vishnu } \\
\text { Rekha y cols. (40) }\end{array}$ & $\begin{array}{l}\text { Estudio } \\
\text { de corte } \\
\text { transversal }\end{array}$ & $\begin{array}{l}\text { La muestra incluyó } \\
\text { una población de } \\
483 \text { niños ( } 363 \text { niños } \\
\text { y } 120 \text { niñas) con } \\
\text { diagnóstico clínico de } \\
\text { autismo. } \\
\text { Edad: entre los } 4 \text { y } \\
16 \text { años } \\
\text { Grupos de estudio: } \\
\text { 1.Dentición temporal } \\
\text { 2. Dentición mixta } \\
\text { 3. Dentición perma- } \\
\text { nente }\end{array}$ & No se reporta & $\begin{array}{l}\text { No se reporta } \\
\text { Compararon un } \\
\text { grupo de niños y niñas } \\
\text { autistas entre los } 4 \\
\text { y } 16 \text { años, en cuanto } \\
\text { a: placa bacteriana, } \\
\text { gingivitis, caries dental, } \\
\text { maloclusión (registro } \\
\text { de la presencia de } \\
\text { apiñamiento, proincli- } \\
\text { nación de los dientes } \\
\text { anteriores, mordida } \\
\text { abierta anterior o } \\
\text { rotaciones), Anomalías } \\
\text { del desarrollo (como } \\
\text { hipoplasia del esmalte, } \\
\text { opacidades en el } \\
\text { diente), alteraciones } \\
\text { orales (frenillo lingual } \\
\text { considerado anquilo- } \\
\text { sado si se insertaba en } \\
\text { la punta de la lengua; } \\
\text { mesiodens: presencia } \\
\text { de un diente extra } \\
\text { entre los incisivos } \\
\text { centrales; la pérdida } \\
\text { de estructura del } \\
\text { esmalte o la dentina se } \\
\text { consideró como una } \\
\text { fractura de Ellis clase } 1 \\
\text { o } 2 \text {, y restauraciones. } \\
\text { Reportan que en } \\
\text { dentición temporal la } \\
\text { proporción de niños y } \\
\text { niñas con maloclusión } \\
\text { fue igual (p=0,371). }\end{array}$ & $\begin{array}{l}\text { No se reporta } \\
\text { Los niños pueden tener } \\
\text { habilidades inadecua- } \\
\text { das para el cuidado } \\
\text { oral o pueden depender } \\
\text { de cuidadores no } \\
\text { calificados para este } \\
\text { fin, lo que resulta en la } \\
\text { acumulación de placa } \\
\text { excesiva y la subsi- } \\
\text { guiente gingivitis. Se ha } \\
\text { demostrado en niños } \\
\text { autistas una mala higie- } \\
\text { ne oral y una mayor } \\
\text { tasa de enfermedades } \\
\text { periodontales y caries } \\
\text { dentales. }\end{array}$ \\
\hline
\end{tabular}




\begin{tabular}{|c|c|c|c|c|c|c|}
\hline Diferencias de las & Cambios de & & & & Grado & \\
\hline $\begin{array}{l}\text { características } \\
\text { craneofaciales según } \\
\text { el grado de severidad } \\
\text { del RM y autismo }\end{array}$ & $\begin{array}{c}\text { características } \\
\text { craneofaciales según } \\
\text { la edad en pacientes } \\
\text { con RM y autismo }\end{array}$ & Resultados & Conclusiones & $\begin{array}{l}\text { Nivel } \\
\text { de Evi- } \\
\text { dencia }\end{array}$ & $\begin{array}{c}\text { de } \\
\text { reco- } \\
\text { men- } \\
\text { dación }\end{array}$ & $\begin{array}{c}\text { Riesgo } \\
\text { de sesgo }\end{array}$ \\
\hline
\end{tabular}

$\begin{array}{ll}\text { No se reporta } & \text { No se reporta } \\ & \text { Reportan que los niños } \\ & \text { autistas con dentición } \\ & \text { permanente tenín } \\ & \text { significativamente más } \\ & \text { maloclusión que los que } \\ & \text { tenían dentición temporal } \\ & \text { o mixta. } \\ & \text { En dentición temporal se } \\ & \text { encontraron niveles más } \\ & \text { altos de caries dental y } \\ & \text { en dentición mixta más } \\ & \text { gingivitis. }\end{array}$

Los niños con desorden
autista con dentición
temporal, mostraron
más caries dental y los
que tenían dentición
mixta y permanente
tenían más gingivitis.

Se sugiere que los

niños con autismo

$3 b$

B

Modera-

reciban cuidado

do riesgo

especial para su

de sesgo

higiene oral, así su

estética dental puede

mejorar.

La mala higiene oral debe ser considera-

da un indicador de

riesgo de caries. Se

ha demostrado en

niños autistas una

mala higiene oral

y una mayor tasa

de enfermedades pe-

riodontales y caries

dentales.

Se puede encontrar

una mayor incidencia

de gingivitis en

dentición mixta y

permanente de los

niños autistas. La

acumulación de

placa pesada y las

influencias hormo-

nales son posibles

explicaciones para

la alta incidencia de

gingivitis en niños

autistas. 


\begin{tabular}{|c|c|c|c|c|c|}
\hline Referencia & $\begin{array}{l}\text { Diseño del } \\
\text { estudio }\end{array}$ & Participantes & $\begin{array}{l}\text { Características en } \\
\text { pacientes con RM }\end{array}$ & $\begin{array}{l}\text { Características } \\
\text { en pacientes con } \\
\text { autismo }\end{array}$ & $\begin{array}{l}\text { Relación causa-efec- } \\
\text { to de hábitos orales } \\
\text { y características } \\
\text { craneofaciales del } \\
\text { RM y autismo }\end{array}$ \\
\hline & & & & $\begin{array}{l}\text { En dentición mixta } \\
\text { y permanente la } \\
\text { proporción de niños } \\
\text { con maloclusión fue } \\
\text { significativamente } \\
\text { mayor que en niñas ( } p \\
=0,000 \text { ) }\end{array}$ & \\
\hline $\begin{array}{l}\text { Periodontal status } \\
\text { and orthodontic } \\
\text { treatment need of } \\
\text { autistic children. } \\
\text { Luppanapornlarp y } \\
\text { cols. (41) }\end{array}$ & $\begin{array}{l}\text { Estudio } \\
\text { observacional }\end{array}$ & $\begin{array}{l}\text { La muestra incluyó } \\
80 \text { niños: } 32 \text { autistas } \\
\text { y } 48 \text { sanos } \\
\text { Edad: entre los } 8 \text { y } \\
\text { los } 12 \text { años de edad. }\end{array}$ & 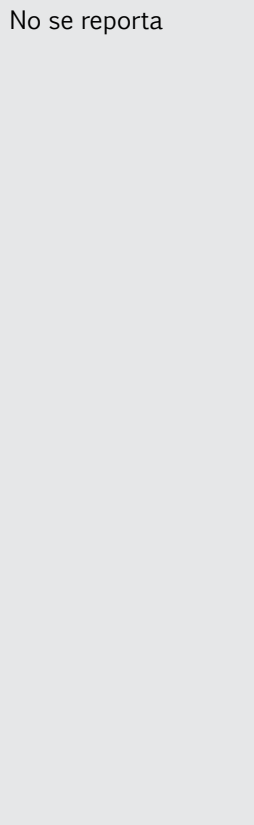 & $\begin{array}{l}\text { No se reporta. } \\
\text { Valoración periodontal } \\
\text { por medio de CPITN. } \\
\text { Valoración dental y ne- } \\
\text { cesidad de tratamiento } \\
\text { ortodóntico, por medio } \\
\text { de la escala de DAI }\end{array}$ & $\begin{array}{l}\text { No se reporta } \\
\text { En niños autistas se } \\
\text { encontraron signos de } \\
\text { maloclusión en mayor } \\
\text { porcentaje, comparado } \\
\text { con los controles. Al } \\
\text { igual, la higiene oral en } \\
\text { niños autistas fue signi- } \\
\text { ficativamente deficiente, } \\
\text { comparada con los } \\
\text { controles. } \\
\text { Estos síntomas pueden } \\
\text { estar relacionados con } \\
\text { la conducta alterada } \\
\text { propia de los pacientes, } \\
\text { tales como chuparse } \\
\text { el dedo, morderse las } \\
\text { uñas/cuerpos extraños, } \\
\text { o autoextracción de } \\
\text { dientes. }\end{array}$ \\
\hline
\end{tabular}




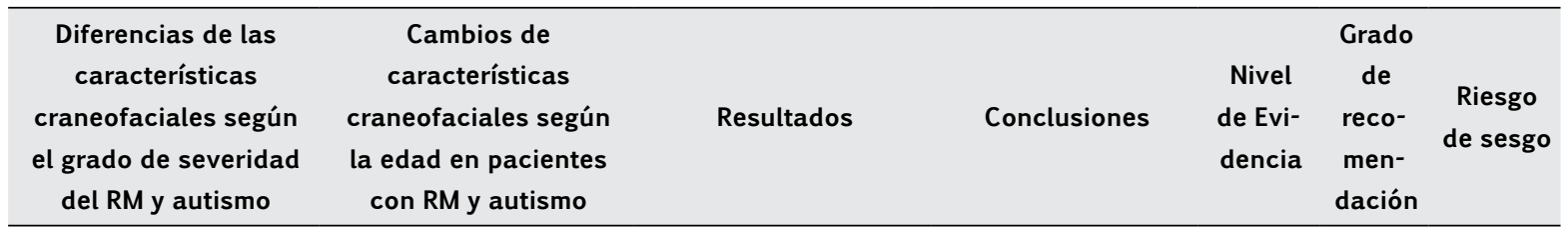

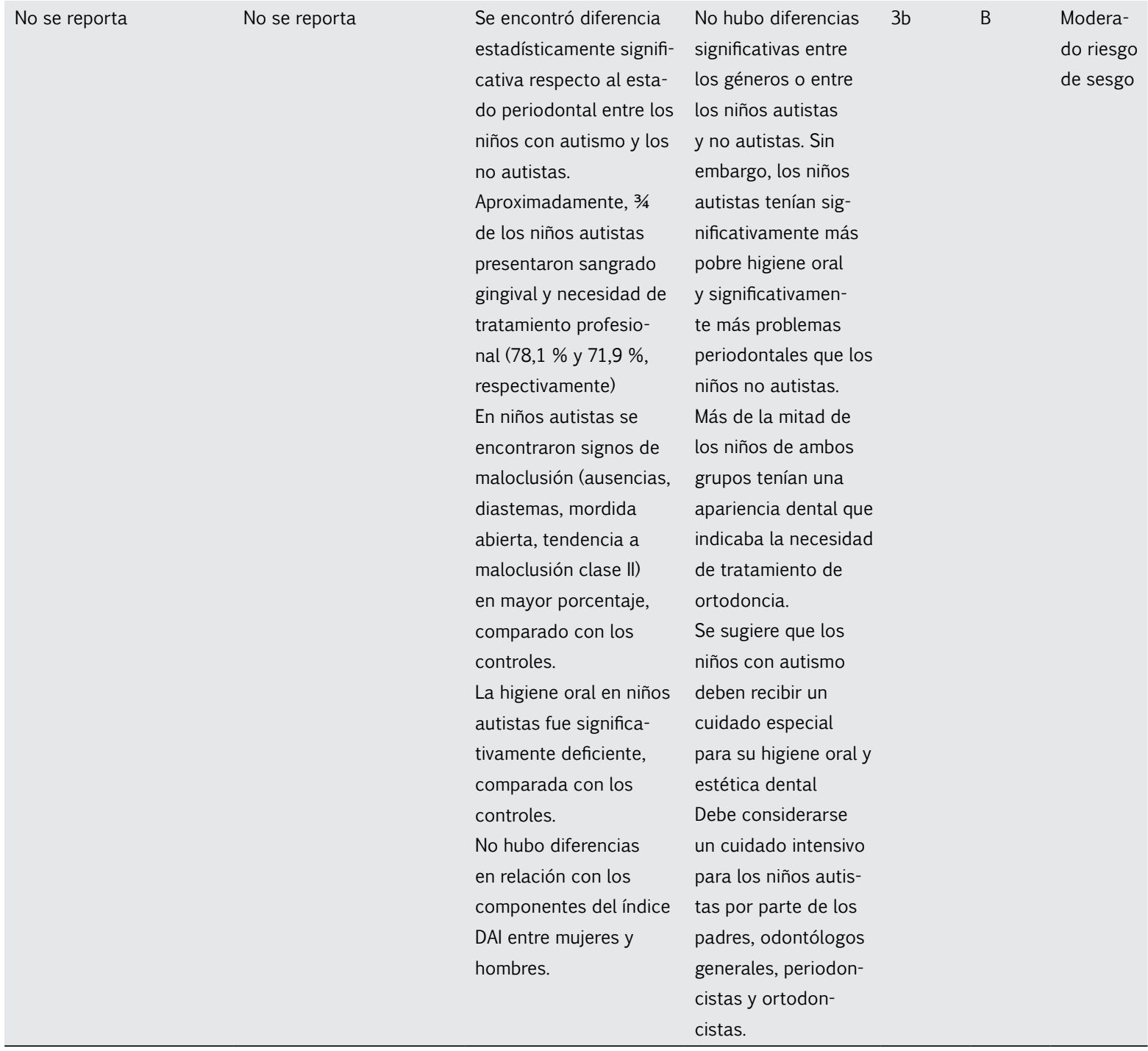


